\title{
Scale effect in Turkish manufacturing industry: stochastic metafrontier analysis
}

\author{
Saeid Hajihassanias| ${ }^{*}$ and Recep Kök ${ }^{2}$
}

\author{
${ }^{*}$ Correspondence: \\ saeidhha@gantep.edu.tr \\ ${ }^{1}$ Faculty of Economics \\ and Administrative Sciences \\ in Islahiye, Department \\ of Economics, Gaziantep \\ University, Gaziantep, Turkey \\ Full list of author information \\ is available at the end of the \\ article
}

\begin{abstract}
Economic theories explain the economic growth affected by accumulation of production factors and increase in productivity and efficiency. Traditional growth theories focus on the first factor where in developing countries, and especially due to the low input of capital, serious problems arise in the growth process. Accordingly, in these countries, increase in the productivity and efficiency and use of the excess capacity has focused. Therefore, the efficiency analysis of economic sectors of these countries, and especially the manufacturing sector and the factors that affect it, is very important to study. The main purpose of this study with respect to the indicators of efficiency of firms operating in Turkey manufacturing industry is to analyze the impact of scale differences on firm performance. The database used in this study is provided from the survey results (2006) belongs to Istanbul OSB, from the balance sheets and income statements of firms registered in IMKB, which operate in Turkey manufacturing industry for the 2006. Furthermore, the database for descriptive analyses was obtained from Statistics Department of Turkey (TUIK) and Turkey's Development Bank. As the analyzing method, the stochastic frontier is used as well as the metafrontier. According to the frontier function scores in the subsectors, in small-scale firms MP, FDT and MEMSAS subsectors and in medium- and large-scale firms OCP, FDT and TSL subsectors are the most efficient subsectors. Also, according to the metafrontier function scores in the subsectors, in small-scale firms MP, MMR and OCP subsectors and in medium- and large-scale firms MP, TSL and OCP subsectors are the most efficient subsectors. Some of the results of this study reveal that, except of food stuffs and drinks (FDT) oil, chemistry, petrochemical and its derivatives (OCP) subsectors, the production inefficiency which occurs in other subsectors due to conditions of increasing return to scale is significantly caused by the operation carried out below the optimal production scale. In addition, except BMI subsector, in all other subsectors, it is seen that production scale has large impact on the efficiency of the firm and also the average efficiency of medium- and large-scale firms in each subsector is higher than the average efficiency of small-scale firms of same subsector.
\end{abstract}

Keywords: Technical efficiency, Technology gap ratio, Stochastic frontier analysis, Turkey's manufacturing industry

JEL Classification: C01, D24, L25

\section{Springer Open}

(c) 2016 Hajihassaniasl and Kök. This article is distributed under the terms of the Creative Commons Attribution 4.0 International License (http://creativecommons.org/licenses/by/4.0/), which permits unrestricted use, distribution, and reproduction in any medium, provided you give appropriate credit to the original author(s) and the source, provide a link to the Creative Commons license, and indicate if changes were made. 


\section{Background}

In today's economics, measuring the efficiency of firms, industry and/or subsector of an industry can largely be observed. At increasing competitive conditions, it is important to measure or assess the efficiency in order to answer the questions such as "How much should a production using limited resources be?" and "How limited resources should be used?" Adapting manufacturing units to these unstable and variable conditions in today's world firstly has considered the competition in terms of efficiency, and then, it has supported the continuation and its related patterns in the macrobalance of the country. Among the methods of increasing production, development of production factors and creating remarkable changes in developing countries' technology are faced with a lot of problems and limitations. Therefore, technical efficiency increase has been mentioned as a better and more adequate solution. Technical efficiency increase can make more production by a fixed set of production factors, and it is of particular importance because of preventing resources from being wasted. In industrial sectors, this issue is of fundamental interest to managers.

Using data from 2006, in this article, it has tried to analyze the efficiency of Turkey manufacturing industry. The most important particular of this article is the study of technical efficiency of manufacturing industries both by sector and for all and also is unveil of how using and evaluating of production factors (labor and capital) in this sector. In addition, due to differences in industrial scale, studying the relationship between technical efficiency and size of production units is important which was examined with technological gap ratio (TGR) approach.

In the first section of the study, the importance and position of the Turkey manufacturing industry will be discussed, and it describes subsectors operating in this sector. In the second step, the conceptual and theoretical framework of efficiency and generally theoretical framework of the study will be discussed. Methodological framework of the study will be introduced in the third step, and the results of the study will be given in the last chapter. Finally, conclusions and policy recommendations will be included.

\section{An overview of the situation of industry and industrial sector in Turkey}

Turkey's manufacturing industries' sector along with the agriculture and services sectors is one of the most important economic and productive sectors. With 1998 fixed prices, having highest contribution of gross domestic product compared to other sectors in the second quarter of 2013 (25.7\%) and also the highest contribution in total exports in the same period (93.5\%) compared to other sectors of the country has increased the importance of this sector.

Manufacturing industries as a dominant sector at industrial sector have been comprised of 22 subsectors. However, considering the act of analyzing in this study, and lack of adequate and distinct information for each subsector, and regarding the classification of statistic center of Turkey (TUIK) and Istanbul's chamber of commerce (ITO), Table 1 is provided within the framework of summarized indexes of this study.

Regarding the statistics related to the years 2005-2010, the annual average of production index in this period, apart from the subsector of textile manufacturing productions and the subsector of oil derivatives, shows increase in other subsectors. Also, in this period, the average change in the labor force using index has decreased in the subsector 
Table 1 Subsectors of Turkey's manufacturing industries (summarized)

\begin{tabular}{ll}
\hline Subsectors & Sector code \\
\hline Foods, drinks and tobacco (FDT) & $15-16$ \\
Textile, spinning, leather and its products (TSL) & $17-18-19$ \\
Wood, paper, print and publication (WPP) & $20-21-22$ \\
Oil, chemical, plastic and caoutchouc (OCP) & $23-24-25$ \\
Mineral products (MP) & 26 \\
Basic metal industries (BMI) & 27 \\
Metal objects, machinery and equipments, office machinery, & $28-29-30-31-32-33-34-35$ \\
$\quad$ radio and TV, optical products, transportation equipments (MMR) & \\
Furniture and other products (FOP) & 36 \\
\hline
\end{tabular}

Source: Turkey statistical Institute and Istanbul Chamber of Commerce

of tobacco production, spinning products, wood and its products, furniture and other products (FOP), as well as in oil derivatives subsector, but it has increased in other subsectors.

Growth rate of exports in this period shows increase in all of the subsectors, and the maximum increase of $23.5 \%$ belongs to the subsector of textile manufacturing productions. On the other hand, import growth rate is also positive in all of the subsectors and the maximum rate of $16.9 \%$ relates to the oil and oil derivatives subsector.

\section{Framework and theoretical foundations}

Generally, efficiency measurement methods can be divided into parametric and nonparametric methods. With nonparametric methods that estimated with linear programming, there is no need for the estimation of any production or cost functions of firms. In efficiency measurements, data envelopment analysis is one of the most important nonparametric methods. In contrast, the parametric methods, firstly, a specific form of production or cost function (as Cobb-Douglas or Translog, etc.) should be determined, and then with econometric methods, coefficients of the function were estimated. In this method, because of determination of parameters of the function discussed, it is called parametric methods (Poor Kazemi and Soltani 2007). ${ }^{1}$

Stochastic frontier parametric methods have many applications in the studies associated with the estimation of technical efficiency which has been developed in the recent years. These methods can distinguish the errors resulted from stochastic effects from the inefficiency effects. Technical efficiency is the ratio of real amounts of production to the maximum of expectable production and assume that other inputs, technology and environmental conditions are constant. Primary models of these methods were developed by Aigner et al. (1977) and Meeusen and van den Brook (1977). Then, these models were developed by Pitt and Lee (1981), Jondrow et al. (1982), and Battese and Coelli (1992, 1995). One of the developments of the recent years is that the assumption of the equality of technology level in manufacturing firms of one industry has been overruled. So, the framework of stochastic metafrontier function has been proposed by Hayami and Ruttan (1970), Battese and Prasada Rao (2002) and Battese et al. (2004). Assuming an

${ }^{1}$ Evaluate the efficiency of Islamic Republic of Iran Railways compared to Asian countries and the Middle East, Journal of Economic Research, No. 78, ss 87-121. 
industry with $K$ group which have different technology levels, using standard methods and the following formula, $K$ number of stochastic frontier function can be estimated:

$$
Y_{i t(k)}=f\left(x_{i t(k)}, \beta_{(k)}\right) \mathrm{e}^{v_{i t(k)}-u_{i t(k)}} \quad i=1,2, \ldots, I_{k} ; \quad t=1,2, \ldots, T ; \quad k=1,2, \ldots, K
$$

where $Y_{i t(k)}$ is the amount of the output of $i$ th firm in the $k$ th group and in $t$ th time. $x_{i t(k)}$ is the vector of the used input amounts by $i$ th firm in the $k$ th group and in $t$ th time. $\beta_{(k)}$ is the vector of unknown parameters that should be estimated for k group. $v_{i t(k)}$ is the statistical residuals which is assumed to be independent from each other, and have random distribution $N\left(0, \sigma_{v(k)}^{2}\right) \cdot u_{i t(k)}$ is a nonnegative random variable, and it is assumed that it has independent distribution $N\left(u_{i t(k)}, \sigma_{u(k)}^{2}\right)$ and it measures the technical inefficiency. Technical efficiency of $i$ th firm in the $k$ th group at the $t$ th time, is obtained through the following expression and according to this, we can assess the efficiency of each firm with return to the frontier of that group (the same group that the firm is contained in it):

$$
\mathrm{TE}_{i t}^{k}=\frac{Y_{i t}}{\mathrm{e}^{x_{i t} \beta_{(k)}+v_{i t(k)}}}=\mathrm{e}^{-u_{i t(k)}}
$$

However, for studying the efficiency of each firm related to the whole of industry (which includes all of the groups with heterogeneous technology), stochastic frontier function should be used (Battese and Prasada Rao 2002).

According to Battese and Prasada Rao (2002) and Battese et al.s (2004) proposed models, a metafrontier production function for an industry is as follows:

$$
Y_{i t}^{*}=f\left(x_{i t}, \beta^{*}\right)=\mathrm{e}^{x_{i t} \beta^{*}} \quad i=1,2, \ldots, \quad I=\sum_{k=1}^{K} I_{k} ; \quad t=1,2, \ldots, T
$$

where $Y_{i t}^{*}$ is the output of metafrontier production function and $\beta^{*}$ is the unknown parameters of metafrontier production function that should be estimated. For all of the amounts of the $\mathrm{k}$ groups (all of the groups with heterogeneous technology), we have $x_{i t} \beta^{*} \geq x_{i t} \beta_{(k)}$ that implies that the metafrontier function is higher on all of the group functions (frontier functions related to the groups) (Prasada Rao et al. 2003). According to (1) and (3) formulas that indicate the group frontier and metafrontier functions, respectively, the following formula can be extracted:

$$
Y_{i t}=\mathrm{e}^{-u_{i t(k)}} \times \frac{\mathrm{e}^{x_{i t} \beta_{i t(k)}}}{\mathrm{e}^{x_{i t} \beta^{*}}} \times \mathrm{e}^{x_{i t} \beta^{*}+v_{i t(k)}}
$$

The right side of the formula (4) has been composed of three parts: The first part of the right side of this formula is the same expression of formula (2), and it indicates the technical efficiency of $i$ th firm at $k$ th group at $t$ th time. The second part of the right side of this formula, based on Battese and Prasada Rao (2002) study, indicates the TGR which is shown as follows:

$$
\mathrm{TGR}_{i t}^{k}=\frac{\mathrm{e}^{x_{i t} \beta_{i t}(k)}}{\mathrm{e}^{x_{i t} \beta^{*}}}
$$


TGR is the output of frontier production function of $k$ th group related to the potential output of metafrontier production function (assuming a certain amount of inputs), and it is between zero and one (Battese et al. 2004). The third part of the formula (4) indicates the technical efficiency of $i$ th firm at the $t$ th time with regard to the metafrontier function, and if it is shown by $\mathrm{TE}_{i t}^{*}$ then using the formulas (2) and (4), the formula (6) can be extracted:

$$
\mathrm{TE}_{i t}^{*}=\mathrm{TE}_{i t}^{k} \times \mathrm{TGR}_{i t}^{k}
$$

For selecting frontier production function as on analysis tool, the forms that are extensively used have been considered and tested. The general form of two kinds of these functions that they have extensively used in the studies and research, i.e., Cobb-Douglas and Translog functions is presented in the following, respectively, based on the Battese and Coeli (1992) definition:

$$
\begin{aligned}
& \ln y_{i(k)}=\beta_{0}+\sum_{j=1}^{2} \beta_{j(k)} \ln x_{i j(k)}+v_{i}^{k}-u_{i}^{k} \\
& \ln y_{i(k)}=\beta_{0}+\sum_{j=1}^{2} \beta_{j(k)} \ln x_{i j(k)}+\frac{1}{2} \sum_{j=1}^{2} \sum_{s=1}^{2} \beta_{j s(k)} \ln x_{i j(k)} \ln x_{i s(k)}+v_{i}^{k}-u_{i}^{k}
\end{aligned}
$$

where $j$ indicates the inputs of $i$ th firm at the $k$ th group $(k=1$ for small firms and $k=2$ for medium and large firms). Also, for all of the $J$ and $K, \beta_{i j(k)}=\beta_{j i(k)}$. In the above formula, $y_{i(k)}$ indicates the value of production of $i$ th firm at $k$ th group, $x_{i 1(k)}$ indicates the number of labor, and $x_{i 2(k)}$ indicates he capital of the $i$ th firm at $k$ th group.

For choosing one of the production functions, maximum likelihood test has been used as follows:

$$
\mathrm{LR}=-2\left\{\ln \left[L\left(H_{0}\right)\right]-\ln \left[L\left(H_{1}\right)\right]\right\}
$$

where $\ln L\left(H_{0}\right)$ indicating the value of the log-likelihood function for the frontier estimating by pooling groups of each subsector and $\ln L\left(H_{1}\right)$ is the sum of the values of the log-likelihood function for the two group-specific frontiers of each subsector. The degree of freedom for Chi-square distribution is the difference between the number of parameters estimated under $H_{0}$ and $H_{1}$.

\section{A review of empirical studies}

One of the main issues that are under consideration in industries is the issue of technical efficiency of producers. Likewise, examining the relationship between technical efficiency and size of productive units, because of diversity in the size of the industries, is of great importance, and in this research, this examination is conducted with technological gap approach. Until now, a lot of research has been conducted on the kinds of efficiency, especially technical efficiency, some of which are as follows:

Mohammed and Alorvor (2004) investigated the technological differences of firms with domestic and foreign capitals in the Gana's manufacturing industries using stochastic frontier analysis and Translog production function. The results showed that technical efficiency of the studied firms in this industry was considerably low. On the other hand, despite the fact that the increased value addition of firms with foreign capitals was 
higher than that of firms with domestic capitals, it is observed that firms having domestic capitals had higher level of efficiency to metafrontier function in comparison with firms having foreign capitals.

Mehrabi Boshrabadi et al. (2006) investigated the technological gap of wheat cultivation in five regions of Kerman province using stochastic frontier analysis and Translog production function. The results revealed that there are considerable differences in the technical efficiency and technological gap of five investigated regions.

In order to examine the efficiency difference and the technology gap in dairy industries, Zibaei and Jaafari Saani (2008) studied metafrontier function approach of data envelopment analysis for five selected provinces. According to the findings of this research, Yazd and Tehran provinces had better condition regarding technology gap in comparison with other provinces.

O'donnell et al. (2008) attempted to evaluate the technological differences in 97 countries, through dividing the countries into four groups and using stochastic metafrontier function and Translog production function. The results of this study demonstrated that there are differences in the amounts of metafrontier technical efficiency and technological gap.

In the framework of metafrontier analysis and using the Cobb-Douglas production function, Repkain (2009) examined the relationship between capital accumulation of telecommunications and total production efficiency. This analysis is considered for four different regions of selected countries.

Dadzie and Dasmani (2010) have used stochastic metafrontier approach using Trans$\log$ production function to investigate the effect of gender on the efficiency of cultivation of food products in Gana. The results of this research show that despite the fact that the efficiency of the units operated by men is high, the efficiency of the units operated by women in comparison with the units run by men has higher levels of efficiency return to metafrontier function.

Villano et al. (2010) estimated technical inefficiency of pistachio cultivators of Kerman Province using Translog production function. According to the results, technical efficiency of gardens of Kalleguchi, Fandoqi, Akbari, and composite gardens are 65.8, 62.4, 59.4 and $78.7 \%$, respectively, and the experience of gardeners was considered as the most important factor that affected efficiency.

Barnes and Revoredo-Giha (2011) evaluated the technological differences in 11 selected European countries using Translog production function. The results of the research reveals that almost all of these countries are close to the frontier of technical efficiency, but they are inefficient return to the metafrontier function that is the technology of European Union.

Fatama Ferdushi et al. (2011) have used metafrontier approach exploiting Translog production function at six different regions for this industry to investigate the technological differences of manufacturing industries of Bangladesh. The findings demonstrated that in addition to the fact that producing efficiency of firms is low, and from the viewpoint of competition in different regions, for explanation of capabilities of one firm, metafrontier function is of great importance.

To access the technological difference in agriculture sector of OECD countries, Tunca (2012) has used the metafrontier approach and data envelopment analysis. The results 
of this study showed that countries with low, middle and high income had used different technology.

In order to study technological differences and the effects of regional technologies in agricultural sector of China, Wang and Hockmann (2012) have used stochastic metafrontier function and Translog production function. The results of this study for three investigated regions reveal that agriculture technology has special and unique regional characteristics.

In the present study, metafrontier function approach has been used for the analysis of the efficiency of Turkey's manufacturing units. Also, besides examining the technological gap, the technical efficiency and the technology gap ratio of manufacturing units in consideration of the size of manufacturing unit were reviewed as well.

\section{Research methodology}

\subsection{Data}

In the economic literature, small, medium and large units are abundantly used as the concept of the size of economic units. There is not a general rule or a standard for distinguishing economic units in this way, like most of the countries, there is not a joint definition or single for dividing economic units and hence attaining a signal viewpoint in Turkey. In this study, for dividing economic units in manufacturing industries of Turkey, the division of the "Ministry of Support and Development of Small, Medium and Large Industries" (KOSGEB) has been considered as the base and groundwork. According to the definition of this ministry, units that employ 1-50 employees are considered as a small unit, units employing 51-150 employees are regarded as medium units and units employing more than 150 employees are considered as large units. Considering this division, and with reference to the available statistics and data for this research, it can be observed that most of the available units are in the group of small or large units and only a few of them are in the group of medium units. For this reason, and also for not facing with the problem of degree of freedom, the medium units will be analyzed and evaluated alongside with large units. Therefore, all of the manufacturing industries of Turkey are summarized in eight subsections, and each of these subsections has been divided into two subgroups of small, medium and large units.

In order to achieve the aims of this research, a model with one output (production value) and two inputs (labor force and capital) has been considered for obtaining frontier production functions. The explanation of each variable is as follows:

\subsubsection{Production value}

The monetary value of output as the production value is little different in small, medium and large units. Since the source of statistics of small units is questionnaire, therefore, the amount of "production value" in questionnaires has been considered. However, in medium and large manufacturing units, the amounts of this variable have been obtained from the sum of "sale value" and "stock value."

On the other hand, in order to purify the effects of the variation or change of general level of prices, the sum of amounts has been divided by the implied gross domestic production of the year, after collecting the statistics related to this variable for all of the units. 


\subsubsection{Labor force}

For this variable, in both small units and medium or large units, the amount associated with "employee's numbers" has been considered. It is important to mention that employee's number refers to the total of the employees that have been working directly or indirectly on production.

\subsubsection{Capital}

Obtaining the data and statistics of capital, as it can be observed in most of the research, is difficult. In this research, the amounts related to variable for small units have been derived from the amount of "total capital" that is available in questionnaires. However, since it has used the information of the stock exchange of Istanbul (IMKB) for medium and large units, the second class statistics have been considered as criterion, so that this amount in the financial statement of firms has involved "physical fixed assets." Here, also, for purifying the effects of the general level of prices, after collecting the statistics related to this variable for all of the units, the total values have been divided by implied gross domestic production of the year 2006.

\subsection{Efficiency indicators' estimation techniques}

In this research, the following three approaches have been used for calculating the technical efficiency and TGRs:

1. Estimation of the standard stochastic frontier production function for mixed data (total firms is performed using FRONTIER version 4.1 software (Coelli 1996), and based on one of the functions (Cobb-Douglas or Translog) and ignoring $k$.

2. Separate stochastic frontier production function estimation for small, medium and large firms of each subsector which is similar to the first approach, but here $k$ is considered in the estimation.

3. Estimation of stochastic metafrontier function coefficients and calculation of technological gap are performed using SHAZEM 8.0 program and based on O'Donnell et al's (2008) programming codes in which data matrix as well as the coefficients of the previous stage and linear programming method is used. The third approach is the most important issue under discussion in this study. Also, based on formula (6) and the calculated technical efficiencies in the second stage and the obtained coefficients from the third stage, the technical efficiency of firms is calculated in comparison with metafrontier production function, i.e., $\mathrm{TE}_{i t}^{*}$.

\subsection{Research hypothesis}

In this study, according to the main purpose of this research, the following hypothesis is intended to be tested:

(a) According to the group analysis, large-scale firms are more efficient than smallscale firms.

(b) Technology gap between firms leads to differences in industrial efficiency. 


\section{Empirical results and discussion}

Since in the present research the generalization of the statistics data of some subsectors was impossible and also for not facing with the problem of degree of freedom for these subsectors, testing the hypothesis for choosing the appropriate model was not possible, so the generalized Cobb-Douglas production function has been used for these subsectors. For other subsectors, however, LR test has been applied for determining the appropriate function for each group separately. The results of hypothesis testing in each subsector reveals that for small firms the Cobb-Douglas function and for medium and large firms Translog function have more consistency and compatibility with studied and reviewed data. To compensate for this difference in choosing appropriate function form for the all groups of the subsectors, estimators have been obtained by using the both functions form. Considering the results of the estimation of the both function forms and referring to Coelli et al's (1998) Parsimory concept, and also because of necessity of same function form use in estimating all functions of each group in each subsector in metafrontier (envelop) function estimation, the most stable function and the most reliable estimators have been considered as analysis parameters and the corresponding form with that estimators has been considered as an acceptable form for that subsector.

The results relevant to the estimated coefficients of stochastic frontier functions are reported in Table 2. Afterward, using the results and coefficients of stochastic frontier functions, and applying the SHAZAM program (for the calculation of the linear programming and coefficients calculation), the coefficients of the metafrontier function have been calculated and the relevant results are presented in the last line or row of Table 2 .

The coefficients obtained from the subsectors, except for OCP and MP subsectors in which the sign of the capital is negative, in other subsectors is consistent with expectations. The negative capital coefficient in the mentioned subsectors can be justified by assuming the acceptability of Translog function for these subsectors. In this regard, considering the acceptability of Translog function in OCP subsectors, we can say that there is excess capital in these subsectors.

Gamma coefficient in all of the small units of the subsectors (except for the subsector of FOP) and in all of the medium and large units (except for the WPP subsector) is significant, and this indicates the inefficiency in all of the subsectors. It is important to mention that because the obtained coefficients were not significant in the wood and paper subsector (WPP) and the subsector of FOP, and because of inadequate degree of freedom, these subsectors were excluded from the analysis.

Regarding the returns to scale values in subsectors, it can be mentioned that regardless of FDT subsectors and OCP subsectors, there is increasing return to scale in other subsectors.

The results related to the kinds of efficiency and technology and technology gap ratio are presented in Table 3 where $\mathrm{TE}^{k}$ indicates the technical efficiency of stochastic frontier functions for small, medium and large firms. TE indicates the technical efficiency of compound stochastic frontier function, TE* indicates the technical efficiency of firms in comparison with metafrontier function, and TGR is the technological gap ratio. Based on the maximum likelihood test, the hypothesis of the equality of frontier function in all 


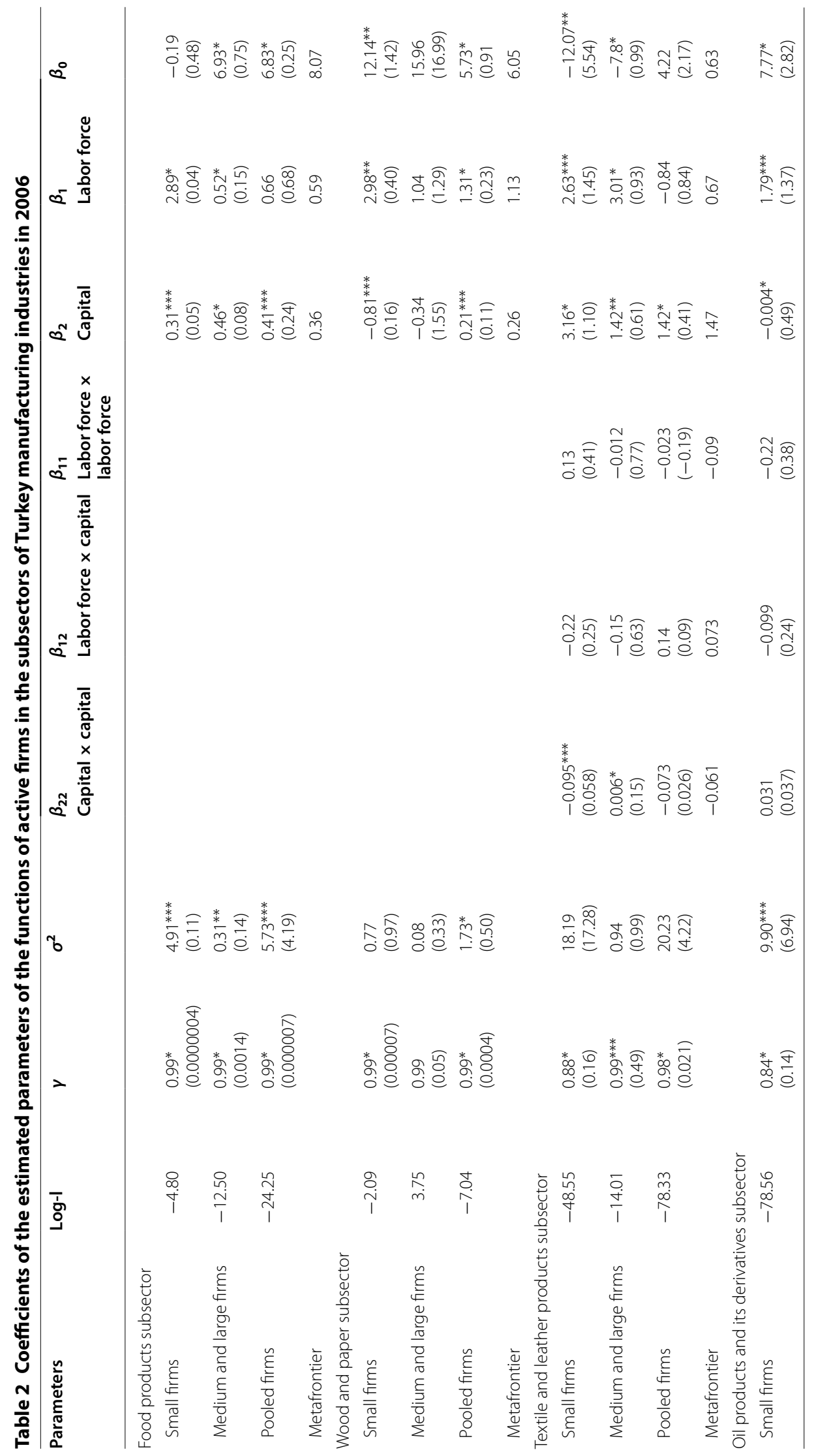




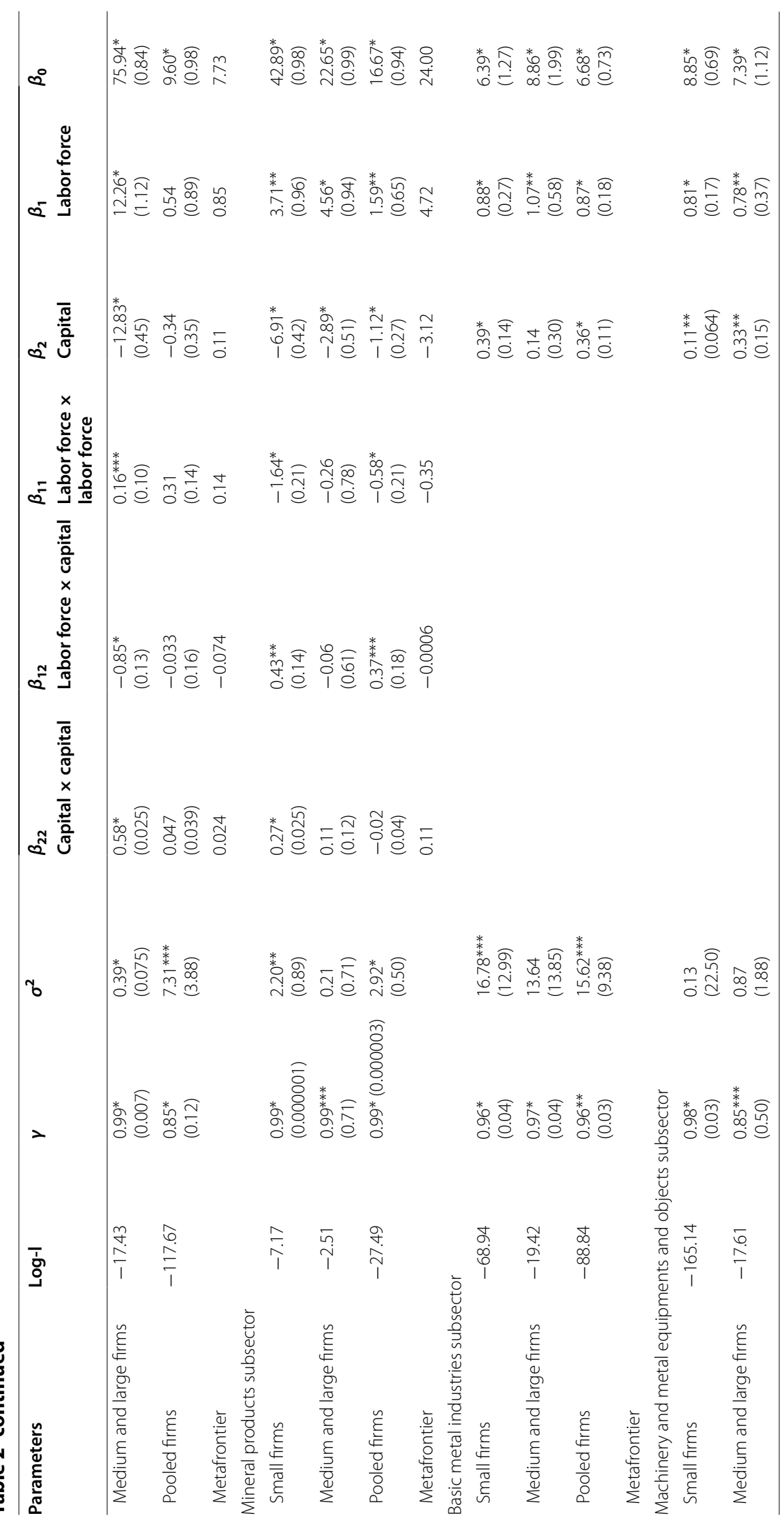




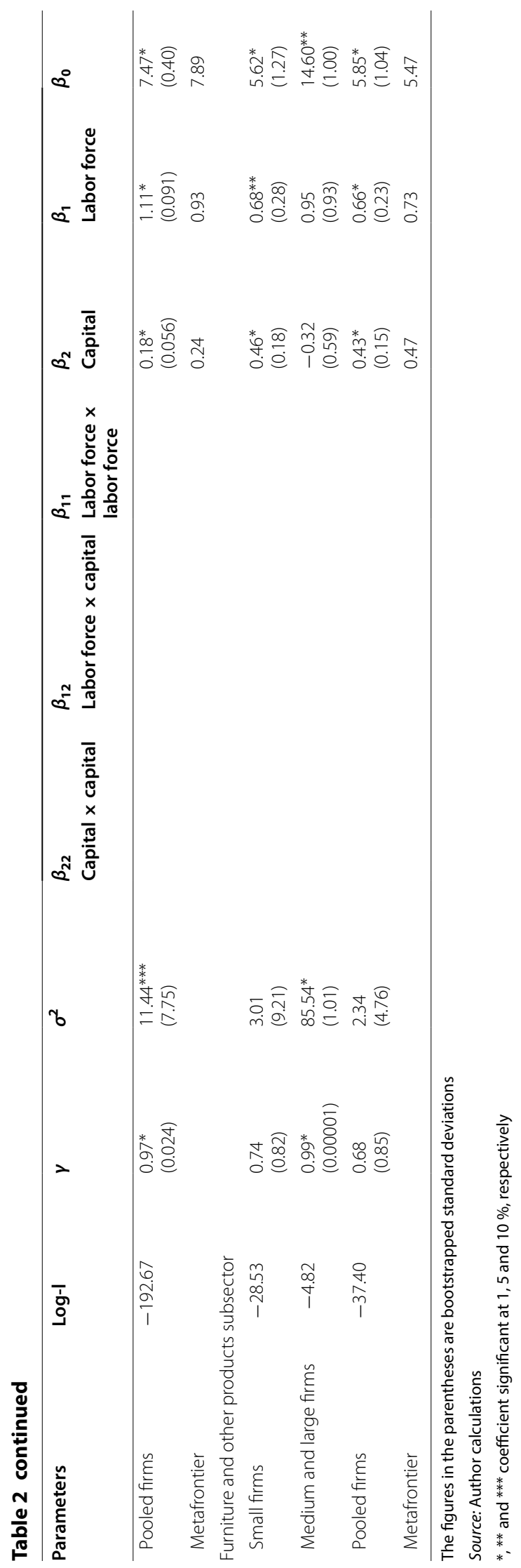


Table 3 Numbers of efficiency and technological gap ratio of active firms in the subsectors of Turkey's manufacturing industry (2006)

\begin{tabular}{|c|c|c|c|c|c|c|c|c|c|c|c|c|}
\hline \multirow[t]{2}{*}{ Model } & \multicolumn{2}{|c|}{$\begin{array}{l}\text { Foods, drinks } \\
\text { and ... }\end{array}$} & \multicolumn{2}{|c|}{$\begin{array}{l}\text { Textile, leather } \\
\text { and ... }\end{array}$} & \multicolumn{2}{|c|}{$\begin{array}{l}\text { Oil products } \\
\text { and ... }\end{array}$} & \multicolumn{2}{|c|}{$\begin{array}{l}\text { Mineral prod- } \\
\text { ucts }\end{array}$} & \multicolumn{2}{|c|}{$\begin{array}{l}\text { Basic metal } \\
\text { industries }\end{array}$} & \multicolumn{2}{|c|}{$\begin{array}{l}\text { Machinery } \\
\text { and ... }\end{array}$} \\
\hline & Small & Large & Small & Large & Small & Large & Small & Large & Small & Large & Small & Large \\
\hline \multicolumn{13}{|l|}{$\mathrm{TE}^{k}$} \\
\hline Min & 0.021 & 0.12 & 0.019 & 0.107 & 0.023 & 0.14 & 0.04 & 0.273 & 0.006 & 0.007 & 0.001 & 0.229 \\
\hline Max & 0.993 & 0.998 & 0.692 & 0.999 & 0.76 & 1 & 1 & 0.997 & 0.77 & 0.789 & 0.83 & 0.879 \\
\hline Mean & 0.727 & 0.486 & 0.39 & 0.566 & 0.47 & 0.492 & 0.694 & 0.715 & 0.392 & 0.443 & 0.403 & 0.606 \\
\hline SD & 0.473 & 0.244 & 0.161 & 0.265 & 0.153 & 0.228 & 0.445 & 0.224 & 0.217 & 0.221 & 0.249 & 0.186 \\
\hline \multicolumn{13}{|l|}{$\mathrm{TE}$} \\
\hline Min & 0.014 & 0.094 & 0.001 & 0.097 & 0.019 & 0.359 & 0.004 & 0.258 & 0.005 & 0.015 & 0.001 & 0.212 \\
\hline Max & 0.985 & 0.999 & 0.841 & 0.637 & 0.812 & 0.736 & 0.869 & 0.999 & 0.781 & 0.722 & 0.826 & 0.812 \\
\hline Mean & 0.344 & 0.474 & 0.335 & 0.459 & 0.485 & 0.553 & 0.344 & 0.65 & 0.396 & 0.425 & 0.415 & 0.543 \\
\hline SD & 0.453 & 0.236 & 0.276 & 0.168 & 0.183 & 0.081 & 0.348 & 0.214 & 0.224 & 0.211 & 0.242 & 0.148 \\
\hline \multicolumn{13}{|l|}{$T E^{*}$} \\
\hline Min & 0.007 & 0.12 & 0.019 & 0.038 & 0.02 & 0.015 & 0.002 & 0.271 & & & 0.001 & 0.193 \\
\hline Max & 0.535 & 0.869 & 0.608 & 0.919 & 0.659 & 0.889 & 1 & 0.995 & & & 0.702 & 0.869 \\
\hline Mean & 0.191 & 0.439 & 0.342 & 0.384 & 0.316 & 0.189 & 0.295 & 0.682 & & & 0.252 & 0.533 \\
\hline SD & 0.246 & 0.219 & 0.155 & 0.24 & 0.171 & 0.198 & 0.345 & 0.214 & & & 0.17 & 0.168 \\
\hline \multicolumn{13}{|l|}{ TGR } \\
\hline Min & 0.007 & 0.793 & 0.532 & 0.031 & 0.079 & 0.029 & 0.017 & 0.919 & & & 0.238 & 0.678 \\
\hline Max & 1 & 1 & 1 & 1 & 1 & 1 & 1 & 1 & & & 1 & 1 \\
\hline Mean & 0.45 & 0.904 & 0.881 & 0.664 & 0.674 & 0.368 & 0.4 & 0.954 & & & 0.63 & 0.883 \\
\hline SD & 0.44 & 0.066 & 0.129 & 0.272 & 0.282 & 0.277 & 0.423 & 0.032 & & & 0.154 & 0.076 \\
\hline
\end{tabular}

Source: Author calculations

of the subsectors, except the basic metal industry (BMI) subsector, was rejected, and this indicates that these functions can separately be estimated.

The LR hypothesis results for all subsectors are shown in Table 4. As revealed in this table, in all subsectors except BMI subsector, same frontier hypothesis of each of the subsector groups has been rejected. This implies that in these subsectors, group frontiers can not be estimated pooled and requires to be estimated metafrontier.

Table 4 LR test results for all subsectors of Turkey manufacturing industry

\begin{tabular}{lccll}
\hline & Log-I & Chi-square & Decision & Results \\
\hline FDT & 13.90 & $11.345^{*}$ & Reject $H_{0}$ & Group frontiers are not same \\
TSL & 31.64 & $16.812^{*}$ & Reject $H_{0}$ & Group frontiers are not same \\
OCP & 43.36 & $16.812^{*}$ & Reject $H_{0}$ & Group frontiers are not same \\
MP & 35.62 & $16.812^{*}$ & Reject $H_{0}$ & Group frontiers are not same \\
BMI & 0.96 & $6.251^{* * *}$ & Accept $H_{0}$ & Group frontiers are same \\
MMR & 19.84 & $11.345^{*}$ & Reject $H_{0}$ & Group frontiers are not same \\
\hline
\end{tabular}

Source: Author calculations

$*$, ** and ${ }^{* * *}$ coefficient significant at 1,5 and $10 \%$, respectively 
Noting that in Table 3, the maximum of TGR in various scales of manufacturing firms equals with 1 , and thus, it can be concluded that stochastic frontier functions of these two groups are tangent to the metafrontier function.

The results obtained for small firms in the subsector of food products (FDT) show that ignoring the hypothesis of technology similarity in the studied firms does not have any significant effect on the development of the fluctuations relevant to the calculation of technical efficiency between firms. The average (mean) of the estimated technical efficiency kinds for small firms indicates the distance of used technology level in this group of firms with the estimated technology for metafrontier function. The obtained results for medium and large firms in this subsector (FDT) indicate that the average of the estimated technical efficiency for medium and large firms in this subsector is close to each other to some extent, and it indicates the closeness of the used technology level in this group of firms with the estimated technology for metafrontier function.

Results for small firms in the subsector of textile and leather products (TSL) reveal that the average of the various estimated technical efficiency for small firms in this subsector is close to each other to some extent, and it indicates the closeness of the technology level used in these groups of firms with the estimated technology for metafrontier function. The average of TGR ( $88 \%$ ) also confirms these results. The obtained results for medium and large firms in this subsector (TSL) indicate that ignoring the assumption of the homogeneity of technology in the studied firms can remarkably have an effect on the development of the fluctuations of technical efficiency calculation between firms. The average of the estimated technical efficiency for medium and large firms in this subsector is close to each other to some extent, and it indicates the closeness of the technology level used in this group of firms with the estimated technology for metafrontier function. This result is also confirmed by the technology gap ratio.

Finding for small firms in the subsector of the oil products and its derivatives (OCP) shows that the average of the estimated technical efficiency of small firms in this subsector is to some extent close to each other, and it indicates the closeness of the technology level used in this group of firms with the estimated technology for metafrontier function. The average of the TGR (67\%) confirms the mentioned proportion. The obtained results for medium and large firms in this subsector (OCP) reveals the change range of technical efficiency is between 1 and $89 \%$ in comparison with the metafrontier function, and this shows that ignoring the assumption of the homogeneity of technology in the studied firms can effectively affect the establishment and development of the fluctuations of technical efficiency calculation between firms. The averages of the estimated technical efficiency for medium and large firms in this subsector are relatively different from each other, and this indicates that the technology level used in this group of firms has distance from the estimated technology for frontier function.

The obtained results for small firms in the subsector of mineral products (MP) indicate that the technical efficiency fluctuates between 0.2 and $100 \%$ in comparison with metafrontier function. This shows that ignoring the assumption of the homogeneity of technology in the studied firms can have significant effect on the development of the fluctuations of technical efficiency calculation among firms. The averages of the estimated technical efficiency for small firms in this subsector are to some extent different from each other, and this shows that the technology level used in this group of firms 
has distance from the estimated technology for frontier function. The low amount of the average of the TGR of ( $40 \%$ ) also confirms the mentioned result. The obtained results for medium and large firms in this subsector (MP) show that the averages of the estimated technical efficiency are to some extent close to each other, and this indicates the closeness of the technology level used in this group of firms with the estimated technology for metafrontier function. This result is also confirmed by the average of the TGR (95\%). However, the technical efficiency is fluctuating between 27 and $99 \%$ in comparison with metafrontier function. This shows that ignoring the assumption of the homogeneity of technology in the studied firms does not have significant effect on the creation and development of the fluctuations of technical efficiency calculation among firms.

Since in the subsector of BMIs the assumption of homogeneity of technology in the studied groups in this subsector was not rejected, so for this subsector the metafrontier function has not been extracted, and therefore, the technical efficiency in comparison with this function and the TGR have not been calculated and investigated. This result is consistent with the current conditions in Turkey's BMIs.

The results obtained for small firms in the subsector of the machinery and metal equipments and objects (MMR) shows that the technical efficiency is fluctuating between 0.1 and $70 \%$ in comparison with metafrontier function. This shows that ignoring the assumption of the homogeneity of technology in the studied firms does not have any significant effect on the development of the fluctuations of technical efficiency calculation between firms. The average of the estimated technical efficiency for small units in this subsector is to some extent close to each other, and it indicates the closeness of the technology level used in this group of firms with the estimated technology for metafrontier function. The obtained results for medium and large firms in this subsector (MMR) indicates that the average of the estimated technical efficiency is to some extent close to each other, and it indicates the closeness of the technology level used in this group of firms with the estimated technology for metafrontier function. This result is confirmed by the average of TGR (88\%). However, the technical efficiency is fluctuating between 19 and $87 \%$ in comparison with metafrontier function. This shows that ignoring the assumption of the homogeneity of technology in the studied firms does not have any significant effect on the development of the fluctuations relevant to technical efficiency calculation among firms.

\section{Conclusion and recommendations}

According to the frontier function scores in the subsectors, in small-scale firms MP, FDT and MEMSAS subsectors and in medium- and large-scale firms OCP, FDT and TSL subsectors are the most efficient subsectors. Also, according to the metafrontier function scores in the subsectors, in small-scale firms MP, MMR and OCP subsectors and in medium- and large-scale firms MP, TSL and OCP subsectors are the most efficient subsectors. Also, except BMI subsector, in all other subsectors, it is seen that production scale has a large impact on the efficiency of the firm and also the average efficiency of medium- and large-scale firms in each subsector is higher than the average efficiency of small-scale firms of same subsector.

According to the obtained results, input-oriented efficiency and technological gaps are different in all of the manufacturing firms of all subsectors. Considering the analytic 
results of this research, except for the subsector of food stuff (FDT) and oil and oil derivatives (OCP), generally in other subsectors there is increasing return to scale and the inefficient production existence in this condition seriously originates from doing producing activities under the optimal production scale. These results, from the viewpoint of Turkey's manufacturing industries, require doing the efficient sector analysis in these industries. Also, it reveals the necessity of taking more efficient policies in this industry. In other words, every active manufacturing firm in each subsector, especially the directors of manufacturing firms with medium scale and large scale, should determine its own competitive scale inside the subsector in the best possible way. In summary, through the discussion on the dynamism of competition power, the main origin of the inefficiency in the local and international markets can be recognized and the situations of doing the more dynamic analysis can be provided.

\section{Author details \\ ${ }^{1}$ Faculty of Economics and Administrative Sciences in Islahiye, Department of Economics, Gaziantep University, Gazi- antep, Turkey. ${ }^{2}$ Faculty of Economics and Administrative Sciences, Department of Economics, Dokuz Eylul University,} Izmir, Turkey.

Received: 14 May 2015 Accepted: 14 March 2016

Published online: 14 April 2016

\section{References}

Aigner DJ, Knox Lovell CA, Schmidt P (1977) Formulation and estimation of stochastic frontier production functions. J Econom 6:21-37

Barnes A, Revoredo-Giha C (2011) A metafrontier analysis of technical efficiency of selected European agricultures. Land Economy Research Group Working Paper No. 109412, Scottish Agricultural College (SAC), UK

Battese GE, Coelli TJ (1992) Frontier production functions, technical efficiency and panel data: with application to paddy farmers in India. J Product Anal 3:153-169

Battes GE, Coelli TJ (1995) A model for technical inefficiency effects in a stochastic frontier production function for panel data. Empir Econ 20:325-332

Battese GE, Prasada Rao DS (2002) Technology gap, efficiency, and a stochastic metafrontier function. Int J Bus Econ $1(2): 87-93$

Battese GE, Prasada Rao DS, O'Donnell CJ (2004) A metafrontier production function for estimation of technical efficiencies and technology gaps for firms operating under different technologies. J Prod Anal 21(1):91-103

Coelli TJ (1996) A guide to FRONTIER version 4.1: A computer program for frontier production function estimation, CEP A Working Paper 96/07. Department of Econometrics, University of New England, Armidale

Coelli TimothyJ, Rao DSP, O'Donnell CJ, Battese GE (1998) An Introduction to efficiency and productivity analysis. Springer, New York

Dadzie SKN, Dasmani I (2010) Gender difference and farm level efficiency: metafrontier production function approach. J Dev Agric Econ 2(12):441-451

Fatama Ferdushi K, Kamil AA, Azizul Baten Md, Mustafa A (2011) Technical efficiency and meta-technology ratios of regional firms in Bangladesh: a stochastic meta-frontier model. Sci Res Essays 6(29):6120-6131

Hayami Y, Ruttan VW (1970) Agricultural productivity differences among countries. Am Econ Rev 60(5):895-911

Jondrow J, Knox Lovell CA, Materov, IS, Schmidt P (1982) On the estimation of technical inefficiency in the stochastic frontier production function model. J Econom 19(2-3):233-238

Meeusen W, van Den Broeck J (1977) Efficiency estimation from Cobb-Douglas production functions with composed error. Int Econ Rev 18(2):435-444

Mehrabi Boshrabadi H, Villano R, Fleming E (2006) Technical efficiency and environmental-technological gaps in wheat production in Kerman Province of Iran. Agric Econ 38(1):67-76

Mohammed A, Alorvor NF (2004) Foreign capital and firm level efficiency in Ghana: a metafrontier production function approach. Unpublished M.Sc. dissertation, School of Economics and Commercial Law, Göteborg University, Sweden

O'Donnell CJ, Rao DSP, Battese GE (2008) Metafrontier a frameworks for the study of firm-level efficiencies and technology ratios. Empir Econ 34(2):231-255

Pitt M, Lee (1981) The measurement and sources of technical inefficiency in the Indonesian weaving industry. J Dev Econ 9(1):43-64

Poor Kazemi MH, Soltani (2007) Evaluate the efficiency of islamic republic of Iran railways compared to Asian and the middle east countries railway. Tahghighat-e Eghtesadi 78:87-121

Prasada Rao DS, O'Donnell Christopher J, Battese GE (2003) Metafrontier functions for the study of inter-regional productivity differences. Working papers series no. 01/2003, School of Economics, University of Queensland, Australia 
Repkine A (2009) Telecommunications capital Intensity and aggregate production efficiency: a meta-frontier analysis. College of Commerce and Economics, Konkuk University, Seoul, South Korea

Tunca H (2012) TürkTarımının OECD Ülkeleri Karşııındaki Rekabet Gücü: Endüstriyel Verimlilik Analizi. Yayınlanmamı̧ Doktora Tezi. Ege Üniversitesi Sosyal Bilimler Enstitüsü, İzmir

Villano R, Mehrabi Boshrabadi H, Fleming E (2010) When is metafrontier analysis appropriate? An example of varietal differences in pistachio production in Iran. J Agric Sci Technol 12(4):379-389

Wang X, Hockmann H (2012) Technical efficiency under producer's individual technology: a metafrontier analysis. In: International Association of Agricultural Economists (IAAE) triennial conference No. 126755. http://ageconsearch. umn.edu/bitstream/126755/2/Hockmann.pdf (12 Nov 2012)

Zibaei M, Jaafari Saani M (2008) Determining of technical efficiency and technological gap ratio in Iran's milk producer units: a case study of meta-frontier application. Agric Sci Tech 12(43):315-324

\section{Submit your manuscript to a SpringerOpen ${ }^{\circ}$} journal and benefit from:

- Convenient online submission

- Rigorous peer review

- Immediate publication on acceptance

- Open access: articles freely available online

- High visibility within the field

- Retaining the copyright to your article

Submit your next manuscript at $\boldsymbol{\nabla}$ springeropen.com 